\title{
No association between polymorphisms/ haplotypes of the vascular endothelial growth factor gene and preeclampsia
}

\author{
Idalia Garza-Veloz ${ }^{1,4}$, Claudia Castruita-De la Rosa', Raul Cortes-Flores², Victoria Martinez-Gaytan², \\ Jose E Rivera-Muñoz ${ }^{1}$, Elda A Garcia-Mayorga', Esteban Meza-Lamas³ ${ }^{3}$ Augusto Rojas-Martinez ${ }^{4,5}$, \\ Rocio Ortiz-Lopez ${ }^{4,5}$ and Margarita L Martinez-Fierro ${ }^{1 *}$
}

\begin{abstract}
Background: Preeclampsia (PE) is the first worldwide cause of death in pregnant women, intra-uterine growth retardation, and fetal prematurity. Some vascular endothelial grown factor gene (VEGF) polymorphisms have been associated to PE and other pregnancy disturbances. We evaluated the associations between VEGF genotypes/ haplotypes and PE in Mexican women.

Methods: 164 pregnant women were enrolled in a case-control study (78 cases and 86 normotensive pregnant controls). The rs699947 (-2578C/A), rs1570360 (-1154G/A), rs2010963 (+405G/C), and rs25648 (-7C/T), VEGF variants were discriminated using Polymerase Chain Reaction - Restriction Fragment Length Polymorphism (PCR-RFLP) methods or Taqman single nucleotide polymorphism (SNP) assays.

Results: The proportions of the minor allele for rs699947, rs1570360, rs2010963, and rs25648 VEGF SNPs were 0.33, $0.2,0.39$, and 0.17 in controls, and $0.39,0.23,0.41$, and 0.15 in cases, respectively ( $P$ values $>0.05$ ). The most frequent haplotypes of rs699947, rs1570360, rs2010963, and rs25648 VEGF SNPs, were C-G-C-C and C-G-G-C with frequencies of $0.39,0.21$ in cases and $0.37,0.25$ in controls, respectively ( $P$ values $>0.05$ )
\end{abstract}

Conclusion: There was no evidence of an association between VEGF alleles, genotypes, or haplotypes frequencies and PE in our study.

\section{Background}

Pre-eclampsia $(\mathrm{PE})$ is a multi-organ disorder defined as elevated blood pressure $(>140 / 90 \mathrm{mmHg})$ and proteinuria that may develop from 20 weeks gestation. PE is the first cause of maternal death in the western world and affects 5 to $8 \%$ of pregnant women, depending on the studied population and definitions of PE [1-3]. The Mexican Secretary of Health Registry reported 278 deaths by PE in 2007 in the country [4].

The etiopathology of PE remains unknown, but improper placentation has been suggested as a possible etiologic factor. This process involves the abnormal infiltration of the cytotrophoblast into the decidual

\footnotetext{
* Correspondence: margaritamf@uaz.edu.mx

1 Laboratorio de Medicina Molecular, Unidad Academica de Medicina Humana y Ciencias de la Salud, Universidad Autonoma de Zacatecas,

Carretera Zacatecas-Guadalajara Km.6. Ejido la Escondida, Zacatecas, Mexico Full list of author information is available at the end of the article
}

endometrium and development of the spiral arteries originated from the myometrium. As a result, the diameter of the spiral arteries enlarge while arteries lose elasticity to allow an increased demand of blood flow to satisfy the intensifying demands of the growing fetus. Improper cytotrophoblast invasion may affect vascular remodelling and blood supply to the fetus, leading to local placental hypoxia [5-7]. Expression of vascular endothelial growth factor (VEGF) has been implied as a hypoxia-induced factor possibly associated to PE, as has been suggested previously [8]. Gu et al. observed increased mRNA and protein levels of VEGF in response to hypoxia in cultured cytotrophoblasts [9]. Zhou et al. found that cytotrophoblast differentiation and invasion during pregnancy is regulated through the VEGF receptor-2. They also found that VEGF regulates cytotrophoblast survival and that expression is deregulated in severe

\section{Biomed Central}


forms of PE.[10] Several authors reported an association between some VEGF polymorphisms and PE in selected populations, with some discrepancies [3,11-14]. No association studies for gene polymorphisms and PE have been reported for the Mexican population, despite the prevalence of this pregnancy disorder in the region. The purpose of the present study was to analyze the association of rs699947 (-2578C/A), rs1570360 (-1154G/A), rs2010963 (+405G/C), and rs25648 (-7C/T) VEGF polymorphisms in a sample of Mexican pregnant women enrolled during 2009-2010.

\section{Methods}

\section{Patients and samples collection}

This study was approved by the Institutional Review Board of the Unidad Medica de Alta Especialidad (UMAE) \# 23 of the Instituto Mexicano del Seguro Social (IMSS) in Monterrey, Mexico. One hundred sixty-four unrelated pregnant women (86 PE cases and 78 normotensive controls), who provided written informed consent for their participation, were enrolled from the High Risk Pregnancy Outpatient Service of the UMAE \# 23 between September 2009 and April 2010. Women between 15-38 years old with singleton pregnancy, 16-38 gestation weeks (GW), who lived in the metropolitan area of Monterrey, were eligible to participate. The PE diagnosis was made according to the guidelines of the International Society for the Study of Hypertension in Pregnancy [15]. In general, these guidelines include two recordings of diastolic blood pressure of $90 \mathrm{mmHg}$ at least $4 \mathrm{~h}$ apart in previously normotensive women and proteinuria of $300 \mathrm{mg}$ or more in $24 \mathrm{~h}$, or two readings of at least ++ on dipstick analyses. PE was considered severe if blood pressure of $160 \mathrm{~mm} \mathrm{Hg}$ systolic or higher or $110 \mathrm{~mm} \mathrm{Hg}$ diastolic or higher on two occasions at least 6 hours apart while the patient was on bed rest, and proteinuria of $5 \mathrm{~g}$ or higher in a 24-hour urine specimen or $3+$ or greater in two random urine samples collected at least 4 hours apart were present [16]. Exclusion criteria included multiple pregnancies, pregnancies with structural or chromosomic fetus malformations detected by ultrasound, chronic hypertension, chronic renal disease, gestational diabetes mellitus, and underlying medical diseases such as rheumatoid arthritis, and systemic lupus erythematosus.

A questionnaire, consisting of demographic and gynecologic data and risk factors (including family history of $\mathrm{PE}$, cardiovascular disease, type 2 diabetes mellitus or autoimmune diseases) was administered to each patient by the participant gynecologist, and a venous blood sample was obtained using EDTA collection tubes. Blood samples were maintained at $4^{\circ} \mathrm{C}$ until their processing.

\section{SNP selection}

Criteria for SNP selection included: SNPs for which an association with PE has been reported in other populations, and considering the potential impact on gene expression only SNPs located in promoter region of VEGF gene or inside its 5'UTR were considered. According to these criteria, rs699947 and rs1570360 variants (located in the VEGF promoter), and rs2010963 and rs25648 (located in 5'UTR of the VEGF gene) were included. Relative to translation start site, the variants rs699947 and rs1570360 are known as $-2578 \mathrm{C} / \mathrm{A}$ and $-1154 \mathrm{G} / \mathrm{A}$, respectively $[17,18]$; while the rs2010963 SNP is called $+405 \mathrm{G} / \mathrm{C}$ (according to mRNA position) or $-634 \mathrm{G} / \mathrm{C}$ (relative to translation start site). In the same sense, rs25648 alternative names are $534 \mathrm{C} / \mathrm{T}$ and $-7 \mathrm{C} / \mathrm{T}$ respectively.

\section{Nucleic acid extraction and genotyping}

DNA was isolated from $1 \mathrm{~mL}$ of blood sample using a standard fenol/chloroform method coupled to ethanol precipitation. Table 1 shows a summary of the genotyping methods employed for the variants screening. PCR coupled to Restriction Fragment Length Polymorphism (PCR-RFLP) method was used to discriminate the rs699947, rs1570360, and rs2010963 VEGF polymorphic variants, respectively. We used the protocols described by Banyasz I et al (rs699947 and rs2010963) [3] and Liu Q et al. (rs1570360) [19], respectively. Some modifications in the primer sequences were included; these modifications are indicated in bold letters in Table 1. All the PCR reactions were made in a volume of $10 \mu \mathrm{l}$ containing $100 \mathrm{ng}$ of genomic DNA, $0.5 \mu \mathrm{M}$ of each primer, and $1 \times$ of GoTaq Colorless Master Mix (Promega: Madison, WI). PCR cycling conditions were as follows: $94^{\circ} \mathrm{C}$ for $5 \mathrm{~min} ; 35$ cycles of $94^{\circ} \mathrm{C}$ for $30 \mathrm{~s}, 60^{\circ} \mathrm{C}$ of annealing temperature for $30 \mathrm{~s}$, and $72^{\circ} \mathrm{C}$ for $30 \mathrm{~s}$; a final extension step of $72^{\circ} \mathrm{C}$ for 5 min was included. PCR products were digested with $B g l$ II (rs699947), $\mathrm{Mnl}$ I (rs1570360), and BsmF I (rs2010963) at $37^{\circ} \mathrm{C}$ (rs699947 and rs1570360) or at $65^{\circ} \mathrm{C}$ (rs2010963) overnight, respectively. The rs699947 and rs2010963 digested products were electrophoresed through 3.5\% agarose gels and visualized by ethidium bromide staining. Digested products of rs1570360 VEGF variant were visualized using the DNA 1000 LabChip kit on the Agilent 2100 Bioanalyzer (Agilent: Palo Alto, CA). Length of PCR and PCR-RFLPs products are shown in Table 1.

The evaluation of the rs 25648 VEGF variant was performed using a predesigned 5 '-nuclease assay with TaqMan MGB probes (Applied Biosystems: Foster City, $\mathrm{CA})$. All reactions were performed in $10 \mu \mathrm{L}$ of volume and $10 \mathrm{ng}$ of genomic DNA. Standard PCR cycling conditions were used and the allelic discrimination was 
Table 1 Genotyping methods description

\begin{tabular}{|c|c|c|c|c|}
\hline SNP ID & Primer sequences* & $\begin{array}{l}\text { Genotyping method } \\
\text { (restriction endonuclease) }\end{array}$ & PCR- RFLP products length (bp) & Referencet \\
\hline rs699947 & $\begin{array}{l}\text { Fw 5'-GCCTTAGGACACCATACCGATG-3' } \\
\text { Rv 5'-GCTGCCCCAGGGAACAAAGTTG-3' }\end{array}$ & $\begin{array}{l}\text { PCR/RFLP } \\
(B g / \|)\end{array}$ & $\begin{array}{c}\text { CC: } 285 \\
\text { CA: } 285,206,79 \\
\text { AA: } 206,79\end{array}$ & Modified from [3] \\
\hline rs1570360 & $\begin{array}{l}\text { Fw 5'-TCCTGCTCCCTCCTCGCCAATG-3' } \\
\text { Rv 5'-GGCGGGGACAGGCGAGCATCAG-3' }\end{array}$ & $\begin{array}{l}\text { PCR/RFLP } \\
(M n l I)\end{array}$ & $\begin{array}{c}\text { AA: } 206 \\
\text { AG: } 206,180,26 \\
\text { GG: } 180,26\end{array}$ & Modified from [19] \\
\hline rs2010963 & $\begin{array}{l}\text { Fw 5'-CCGACGGCTTGGGGAGATTGCTC-3' } \\
\text { Rv 5'-CGGCGGTCACCCCCAAAAGCAG-3' }\end{array}$ & $\begin{array}{l}\text { PCR/RFLP } \\
(B s m F 1)\end{array}$ & $\begin{array}{l}\text { GG: } 157,40 \\
\text { GC: } 197,157,40 \\
\text { CC: } 197\end{array}$ & Modified from [3] \\
\hline rs 25648 & - - & Real time PCR Taqman assay & - - & hCV791476 \\
\hline
\end{tabular}

*Nucleotides in bold letters in primer sequences indicate primer modifications included in this study. Original references of primer sequences and protocols.

made using the StepOne RT-PCR system with the StepOne v2.0 software (Applied Biosystems).

All the SNPs were validated by direct sequencing of PCR products obtained from four patients using BigDye Terminator v3.1 Cycle Sequencing Kit (Applied Biosystems), and analyzed in an Avant 3100 Genetic Analyzer. To ensure reliability of the results, duplicate samples and known genotyped samples were included in the analysis as quality controls.

\section{Data Analysis}

General variables of the study groups such as maternal age, gestational age, and number of pregnancies, were compared using the Student's $t$ test. In the control group, SNPs genotypes were tested for departures from Hardy-Weinberg equilibrium by exact test. To compare known risk factors, allele, and genotype frequencies between the study groups, a chi-square test was performed. Linkage disequilibrium statistics and haplotypes analysis, including haplotypes frequency estimation, as well as an analysis of association between haplotypes and PE, were made using SNPStats software http:// bioinfo.iconcologia.net/index.php? module=Snpstats. The Odds Ratio (OR) values were calculated for each allele, genotype, and haplotype. For the adjustment of gestational age, logistic regression analysis was used to compare allele and genotype frequencies between PE and the control group. Study power was calculated at the end of the study using Quanto software v1.2.4 [20]. For each SNP we considered its minor allele frequency as reported in the Mexican HapMap project. Depending on the SNP, in the analysis an effect of size 2 or greater was established.

The level of significance was set at $P<0.05$. Statistical analysis was performed using Sigma Plot software v11.

\section{Results}

One hundred and sixty four unrelated pregnant women (86 PE cases and 78 normotensive controls) were included in the study. The comparison among the general variables of the study population (Table 2) showed that gestational age was the only variable associated to PE $(P=0.028)$. We did not find an association between known risk factors and PE $(P>0.05)$. Genotype frequencies for all the SNPs included in the study were in Hardy-Weinberg equilibrium in the controls $(P>$ 0.05). Table 3 displays the genotypes and minor allele frequencies for each SNP in cases and controls. The proportions for the minor allele for rs699947, rs1570360, rs2010963, and rs25648 VEGF SNPs were $0.33,0.2,0.39$, and 0.17 in controls, and 0.39, 0.23, 0.41, and 0.15 in cases, respectively (Table 3 ). We did not observe significant differences between individual genotypes or allele frequencies of the studied VEGF SNPs in the cases and control groups ( $P$ values $>0.05)$.

In a statistical approximation, an association between genotype/allele frequencies and severity of the disease was not found (table S1 of Additional file 1). To test the association between PE onset and VEGF genotype variants, the group of severe PE patients was classified in early and late PE, with a cut off at $35 \mathrm{GW}$. Again, no association between VEGF genotypes and PE onset was found ( $P$ values $>0.05$; data not shown).

Table 2 Demographic variables and risk factors of the study population

\begin{tabular}{|c|c|c|c|}
\hline Characteristic & $\begin{array}{l}\text { Controls } \\
(\mathrm{n}=78)\end{array}$ & $\begin{array}{l}\text { PE cases } \\
(\mathrm{n}=86)\end{array}$ & $\begin{array}{c}P \\
\text { value }\end{array}$ \\
\hline Maternal age, mean (range) years & $5(17-36)$ & $27(15-38)$ & 0.067 \\
\hline Gestational age, median (range) weeks & $32(16-38)$ & $34(17-37)$ & $0.028^{*}$ \\
\hline Number of pregnancies, median (range) & $2(1-6)$ & $2(1-5)$ & 0.614 \\
\hline Family history of $\mathrm{PE}, \mathrm{n}(\%)$ & $5(6.4)$ & $7(8.1)$ & 0.337 \\
\hline $\begin{array}{c}\text { Family history of type } 2 \text { Diabetes } \\
\text { mellitus, } \mathrm{n}(\%)\end{array}$ & $24(30.76)$ & $35(40.7)$ & 0.784 \\
\hline $\begin{array}{l}\text { Family history of arterial hypertension, } \\
\qquad \mathrm{n}(\%)\end{array}$ & $31(39.74)$ & $37(43.02)$ & 0.409 \\
\hline Primipaterr & $24(30.76)$ & $27(28.13)$ & 0.531 \\
\hline $\begin{array}{l}\text { Use of barrier contraceptive method, } \\
\qquad \mathrm{n}(\%)\end{array}$ & $29(37.18)$ & $28(33.55)$ & 0.392 \\
\hline Nulliparous, n (\%) & $28(35.89)$ & $35(40.69)$ & 0.995 \\
\hline
\end{tabular}


Table 3 Comparison of allele and genotype frequencies between study groups

\begin{tabular}{cccccc}
\hline $\begin{array}{c}\text { dbSNP } \\
\text { ID }\end{array}$ & $\begin{array}{c}\text { Genotype } \\
\text { and minor } \\
\text { allele }\end{array}$ & $\begin{array}{c}\text { Controls } \\
(\mathbf{n}=\mathbf{7 8})\end{array}$ & $\begin{array}{c}\text { PE } \\
\text { Cases } \\
(\mathbf{n}=\mathbf{8 6})\end{array}$ & OR (Cl 95\%) & $\begin{array}{c}\boldsymbol{P} \\
\text { value }\end{array}$ \\
\hline rs699947 & CC & $35(0.45)$ & $29(0.34)$ & $0.75(0.27-2.08)$ & 0.31 \\
& CA & $34(0.44)$ & $47(0.55)$ & & \\
rs1570360 & AA & $9(0.11)$ & $10(0.11)$ & & \\
& Allele A & $52(0.33)$ & $67(0.39)$ & $0.78(0.49-1.23)$ & 0.34 \\
& GG & $49(0.63)$ & $51(0.59)$ & $0.94(0.49-1.80)$ & 0.57 \\
rs2010963 & GA & $27(0.35)$ & $30(0.35)$ & & \\
& AA & $2(0.02)$ & $5(0.06)$ & & \\
& Allele A & $31(0.2)$ & $40(0.23)$ & $0.82(0.48-1.38)$ & 0.54 \\
& GG & $26(0.33)$ & $28(0.33)$ & $1.03(0.52-2.03)$ & 0.79 \\
rs25648 & GC & $43(0.55)$ & $45(0.52)$ & & \\
& CC & $9(0.12)$ & $13(0.15)$ & & \\
& Allele C & $61(0.39)$ & $71(0.41)$ & $0.91(0.58-1.42)$ & 0.77 \\
& CC & $55(0.70)$ & $62(0.72)$ & $0.98(0.49-1.98)$ & 0.53 \\
& CT & $20(0.26)$ & $23(0.27)$ & & \\
& TT & $3(0.04)$ & $1(0.01)$ & & \\
& Allele T & $26(0.17)$ & $25(0.15)$ & $1.17(0.64-2.13)$ & 0.70 \\
\hline
\end{tabular}

To study the association between PE and possible combinations of the $V E G F$ variants, we performed a haplotype analysis on for the four VEGF SNPs. A linkage disequilibrium (LD) test, showed a LD association between the rs699947, rs1570360, rs2010963, and rs25648 VEGF variants (D'>0.87, range: 0.882 to $0.998 P<0.001)$. The data for D'statistic of each pairwise of SNPs and its p values are shown in table S2 of Additional file 2. A comparison between haplotypes frequencies of VEGF SNPs and their association with $\mathrm{PE}$ is summarized in Table 4. Five major combinations between VEGF SNPs studied were determined; four of them with frequencies above $10 \%$ (C-G-C-C, C-G-G-C, A-A-G-C, and A-G-G-T for rs699947, rs1570360, rs2010963, and rs25648 VEGF SNPs, respectively) and one of them, A-G-G-C, with a frequency of $1.5 \%$.

The $P$ values for individual and global haplotype score tests (Table 4) did not indicate a significant difference in $V E G F$ haplotype frequency profiles between cases and controls $(P>0.05)$.

Considering the sample size of 164 , the study power was calculated in a range of $45.19 \%$ to $65.96 \%$ to detect an effect of size 2 or greater depending on the SNP considered.

\section{Discussion}

Genetic predisposition is a well-documented risk factors for PE [21,22]; however, although several genes have been postulated as genetic susceptibility markers of the disease [21-24], there is not a recognized hereditary profile to explain the association [21]. Considering differences in genetic predisposition between populations and the important role of $V E G F$ gene in the angiogenesis during the pregnancy, we conducted a case-control study, to test the association between the rs699947, rs1570360, rs2010963, and rs25648 VEGF genetic variants and PE. Consistent with the lack of association between -2578C/A (rs699947) VEGF genotypic/allelic frequencies in women with severe PE reported by Papazoglou D et al (2004) in Greece [13], we did not find an association between genotype/allele frequencies of the studied SNPs and PE or with severity of the disease $(P>$ 0.05). However, our results contrasted with those reported by Sandrim VC et al. (2009) for Caucasic Brazilian women, who reported a positive association between -2578C/A (but not for -1154G/A) genotypes and PE [12]. Banyasz I et al (2006) suggested that carriers of the VEGF+405G (rs2010963) allele in an Hungarian population have a decreased susceptibility to $\mathrm{PE}$ and while carriers of the VEGF-2578A (rs699947) allele could be associated with an accelerated development of the disease in nulliparous pregnant women with severe PE [3]. In our study, carriers of the VEGF+405G (rs2010963) allele did not have a decreased susceptibility to PE and no association was found between allele/genotypes frequencies of the studied VEGF variants (including VEGF-2578 C/A) and PE onset. Discrepancies of $V E G F$ allele/genotype frequencies and their association with PE, severity, or onset of disease, may be explained

Table 4 Analysis of haplotypes frequencies and their association with PE

\begin{tabular}{cccccccc}
\hline & \multicolumn{9}{c}{ SNP } & & & \\
Haplotype* & rs699947 & rs1570360 & rs2010963 & rs25648 & Freq & OR (95\% Cl) & P value \\
\hline 1 & C & G & G & C & C & 0.3851 & 1 \\
2 & C & G & G & C & 0.2308 & $1.31(0.72-2.39)$ & 0.38 \\
3 & A & A & G & C & 0.1953 & $0.72(0.37-1.37)$ & 0.31 \\
4 & A & G & G & T & 0.1358 & $0.92(0.44-1.96)$ & 0.84 \\
5 & A & G & G & C & 0.015 & $1.63(0.33-8.13)$ & 0.55
\end{tabular}


in part by the ethnic variability between populations and by differences in selection criteria of the studied groups. For example, the lack of consensus in the controls selection, which has included post-menopausal women with a history of at least two uncomplicated pregnancies, nulliparous pregnant women, women with uncomplicated pregnancies, or normotensive pregnant women, makes difficult the comparison between studies and may include some bias in the association reports.

PE susceptibility related to VEGF haplotypes has been considered in a very few studies; however, none of them has genotyped all the variants included in this work. We did not find differences in the identified haplotypes profiles between cases and controls. In contrast with our results, Sandrim VC et al. (2009) suggested a protective effect for the $-2578 \mathrm{C},-1154 \mathrm{G}$ and $-634 C$ haplotype (associated with higher VEGF gene expression) against the development of PE [12]. In our study, we did not include the -634G/C variant; however, although we performed a statistical analyses in which only the $-2578 \mathrm{C} / \mathrm{A},-1154 \mathrm{G} / \mathrm{A}$ SNPs were considered for this analysis, the lack of association between VEGF haplotypes frequencies and PE was consistent. Finally, some considerations should be highlighted: One of the major limitations of this work was the small sample size because it influenced the study power (calculated in a range of $45.19 \%$ to $65.96 \%$ depending on the SNP studied). In this same sense, the limited sample size affects the association analyses performed in sub-classified groups, as PE severity or $\mathrm{PE}$ onset, since sub-classifications reduced the numbers of study subjects and could introduce some bias in the statistical analysis. In our, study the nulliparous state was not considered as selection criteria or was subclassified for additional comparisons; however, this PE risk factor showed no difference between groups. Our control group included normotensive women, but their "current healthy pregnant state" does not discard the future presence of PE pregnancies.

In Mexico, there are no data about genetic susceptibility for PE associated to VEGF variants. Our study is the first protocol that evaluated the possible association between VEGF genotypes/haplotypes and PE, and the results obtained in the study suggest the presence of additional genetic variants different from rs699947, rs1570360, rs2010963, and rs25648 VEGF as markers for the genetic susceptibility to PE.

\section{Conclusion}

In our study, there was no evidence of an association between allele, genotype or haplotype frequencies and $\mathrm{PE}$, its severity or onset of the disease.

\section{Additional material}

Additional file 1: Comparison of alleles, genotypes, and haplotypes frequencies between study groups, according to disease severity.

Additional file 2: Linkage Disequilibrium Analysis. $D^{\prime}$ statistics and $P$ values for each parwise of VEGF variants included in the study.

\section{Acknowledgements}

We thank all the study participants. Authors thank M. en C. Alfredo Salazar de Santiago and Dra. Ma. del Carmen Aceves Medina from Area de Ciencias de la Salud (Universidad Autonoma de Zacatecas) for their contributions and support. This work was supported in part from FOMIX CONACYT-Gobierno del Estado de Zacatecas Grant, (ID number: 121535).

\section{Author details}

${ }^{1}$ Laboratorio de Medicina Molecular, Unidad Academica de Medicina Humana y Ciencias de la Salud, Universidad Autonoma de Zacatecas, Carretera Zacatecas-Guadalajara Km.6. Ejido la Escondida, Zacatecas, Mexico.

${ }^{2} U$ nidad Medica Materno-Fetal del Noreste, Unidad Medica de Alta Especialidad No. 23 Instituto Mexicano del Seguro Social, Avenida Constitucion y Felix U. Gomez, Col. Centro, Monterrey, Mexico. ${ }^{3}$ Unidad Academica de Enfermeria, Universidad Autonoma de Zacatecas, Carretera Zacatecas-Guadalajara Km.6. Ejido la Escondida, Zacatecas, Mexico.

${ }^{4}$ Department of Biochemistry and Molecular Medicine, University Hospital Universidad Autonoma de Nuevo Leon, Av. F. I. Madero S/N, Col. Mitras Centro, Monterrey, Mexico. ${ }^{5}$ Centro de Investigacion y Desarrollo en Ciencias de la Salud, Universidad Autonoma de Nuevo Leon, Calle Carlos Canseco S/ N, Col. Mitras Centro, Monterrey, Mexico.

\section{Authors' contributions}

IGV and CCDLR carried out the samples processing and the molecular genetic studies, IGV drafted the manuscript. RCF and VMG participated in the design of the study and in the coordination of patient recruitment. JERM, EAGM, and EML participated in data acquisition, analysis and interpretation, and reviewed the manuscript. ARM and ROL were involved in the design of the study and in the preparation of the manuscript. MLMF conceived the study, participated in its design and coordination, performed the statistical analysis, and helped to draft the manuscript. All authors read and approved the final manuscript.

\section{Competing interests}

The authors declare that they have no competing interests. The authors are responsible for the content and writing of the research paper.

Received: 18 January 2011 Accepted: 16 May 2011

Published: 16 May 2011

\section{References}

1. Sibai BM, Stella CL: Diagnosis and management of atypical preeclampsiaeclampsia. Am J Obstet Gynecol 2009, 200(5):481.e1-481.e7.

2. Sibai B, Dekker G, Kupferminc M: Pre-eclampsia. Lancet 2005, 365(9461):785-799.

3. Banyasz I, Szabo S, Bokodi G, Vannay A, Vasarhelyi B, Szabo A, Tulassay T, Rigo J Jr: Genetic polymorphisms of vascular endothelial growth factor in severe pre-eclampsia. Mol Hum Reprod 2006, 12(4):233-236.

4. (SINAIS) SNdleS: Principales causas de mortalidad materna en México, 2005-2007. 2007 [http://sinais.salud.gob.mx/descargas/xls/

Princip_CausasMM_2005-2007.xIs].

5. Geusens N, Verlohren S, Luyten C, Taube M, Hering L, Vercruysse L, Hanssens M, Dudenhausen JW, Dechend R, Pijnenborg R: Endovascular trophoblast invasion, spiral artery remodelling and uteroplacental haemodynamics in a transgenic rat model of pre-eclampsia. Placenta 2008, 29(7):614-623.

6. Jauniaux E, Poston L, Burton GJ: Placental-related diseases of pregnancy: Involvement of oxidative stress and implications in human evolution. Hum Reprod Update 2006, 12(6):747-755. 
7. Roberts JM, Taylor RN, Musci TJ, Rodgers GM, Hubel CA, McLaughlin MK: Preeclampsia: an endothelial cell disorder. Am J Obstet Gynecol 1989, 161(5):1200-1204.

8. Li H, Gu B, Zhang Y, Lewis DF, Wang Y: Hypoxia-induced increase in soluble Flt-1 production correlates with enhanced oxidative stress in trophoblast cells from the human placenta. Placenta 2005, 26(23):210-217.

9. Gu Y, Lewis DF, Wang Y: Placental productions and expressions of soluble endoglin, soluble fms-like tyrosine kinase receptor-1, and placental growth factor in normal and preeclamptic pregnancies. J Clin Endocrinol Metab 2008, 93(1):260-266.

10. Zhou Y, McMaster M, Woo K, Janatpour M, Perry J, Karpanen T, Alitalo K, Damsky C, Fisher SJ: Vascular endothelial growth factor ligands and receptors that regulate human cytotrophoblast survival are dysregulated in severe preeclampsia and hemolysis, elevated liver enzymes, and low platelets syndrome. Am J Pathol 2002, 160(4):1405-1423.

11. Srinivas SK, Morrison AC, Andrela CM, Elovitz MA: Allelic variations in angiogenic pathway genes are associated with preeclampsia. Am $J$ Obstet Gynecol 202(5):445-e441-411.

12. Sandrim VC, Palei AC, Cavalli RC, Araujo FM, Ramos ES, Duarte G, TanusSantos JE: Vascular endothelial growth factor genotypes and haplotypes are associated with pre-eclampsia but not with gestational hypertension. Mol Hum Reprod 2009, 15(2):115-120.

13. Papazoglou D, Galazios G, Koukourakis MI, Panagopoulos I, Kontomanolis EN, Papatheodorou K, Maltezos E: Vascular endothelial growth factor gene polymorphisms and pre-eclampsia. Mol Hum Reprod 2004, 10(5):321-324.

14. Kim YJ, Park BH, Park H, Jung SC, Pang MG, Ryu HM, Lee KS, Eom SM, Park HY: No association of the genetic polymorphisms of endothelial nitric oxide synthase, dimethylarginine dimethylaminohydrolase, and vascular endothelial growth factor with preeclampsia in Korean populations. Twin Res Hum Genet 2008, 11(1):77-83.

15. Brown MA, Lindheimer MD, de Swiet M, Van Assche A, Moutquin JM: The classification and diagnosis of the hypertensive disorders of pregnancy: statement from the International Society for the Study of Hypertension in Pregnancy (ISSHP). Hypertens Pregnancy 2001, 20(1):IX-XIV.

16. ACOG practice bulletin. Diagnosis and management of preeclampsia and eclampsia. Number 33, January 2002. Obstet Gynecol 2002, 99(1):159-167.

17. Brogan IJ, Khan N, Isaac K, Hutchinson JA, Pravica V, Hutchinson IV: Novel polymorphisms in the promoter and 5' UTR regions of the human vascular endothelial growth factor gene. Hum Immunol 1999, 60(12):1245-1249.

18. Jain L, Vargo CA, Danesi R, Sissung TM, Price DK, Venzon D, Venitz J, Figg WD: The role of vascular endothelial growth factor SNPs as predictive and prognostic markers for major solid tumors. Mol Cancer Ther 2009, 8(9):2496-2508.

19. Liu Q, Li Y, Zhao J, Sun DL, Duan YN, Wang N, Zhou RM, Kang S: Association of polymorphisms $-1154 \mathrm{G} / \mathrm{A}$ and $-2578 \mathrm{C} / \mathrm{A}$ in the vascular endothelial growth factor gene with decreased risk of endometriosis in Chinese women. Hum Reprod 2009, 24(10):2660-2666.

20. Gauderman W, Morrison J: QUANTO 1.1: A computer program for power and sample size calculations for genetic-epidemiology studies. 2006 [http://hydra.usc.edu/gxe/].

21. Chappell S: Searching for genetic clues to the causes of pre-eclampsia. Clinical science (London, England: 1979) 2006, 110(4):443-458.

22. Goddard KA, Tromp G, Romero R, Olson JM, Lu Q, Xu Z, Parimi N, Nien JK, Gomez R, Behnke E, Solari M, Espinoza J, Santolaya J, Chaiworapongsa T, Lenk GM, Volkenant K, Anant MK, Salisbury BA, Carr J, Lee MS, Vovis GF, Kuivaniemi $\mathrm{H}$ : Candidate-gene association study of mothers with preeclampsia, and their infants, analyzing 775 SNPs in 190 genes. Hum Hered 2007, 63(1):1-16.

23. Bombell S, McGuire W: Tumour necrosis factor (-308A) polymorphism in pre-eclampsia: meta-analysis of 16 case-control studies. Aust N Z J Obstet Gynaecol 2008, 48(6):547-551

24. Dissanayake VH, Giles V, Jayasekara RW, Seneviratne HR, Kalsheker N, Broughton Pipkin F, Morgan L: A study of three candidate genes for preeclampsia in a Sinhalese population from Sri Lanka. J Obstet Gynaecol Res 2009, 35(2):234-242.

\section{Pre-publication history}

The pre-publication history for this paper can be accessed here: http://www.biomedcentral.com/1471-2393/11/35/prepub

doi:10.1186/1471-2393-11-35

Cite this article as: Garza-Veloz et al:: No association between polymorphisms/haplotypes of the vascular endothelial growth factor gene and preeclampsia. BMC Pregnancy and Childbirth 2011 11:35.

\section{Submit your next manuscript to BioMed Central and take full advantage of:}

- Convenient online submission

- Thorough peer review

- No space constraints or color figure charges

- Immediate publication on acceptance

- Inclusion in PubMed, CAS, Scopus and Google Scholar

- Research which is freely available for redistribution

Submit your manuscript at www.biomedcentral.com/submit
Biomed Central 